\title{
Biologic Therapy for Psoriasis in the Era of COVID-19 Pandemic: To Stop or to Continue?
}

\author{
Ahmed M. Abbas s.2* $^{12}$ and Zeinab Y. Zaki ${ }^{2,3}$ \\ ${ }^{1}$ Department of Obstetrics \& Gynecology, Faculty of Medicine, Assiut University, Egypt \\ ${ }^{2}$ Covid-19 Research of Assiut University Association (CORAUNA) group, Egypt \\ ${ }^{3}$ House-officer, Faculty of Medicine, Assiut University, Egypt
}

Dear editor,

Coronavirus disease-19 (COVID-19) is a clinical syndrome caused by a novel coronavirus called Sever acute respiratory syndrome coronavirus 2 (SARS-CoV-2) [1]. On $31^{\text {st }}$ December, 2019, numerous of cases of pneumonia of unknown etiology were reported in Wuhan, China. After that, COVID-19 has spread rapidly world-wide and has been shown to have a wide spectrum of severity. It was declared as a pandemic by the World Health Organization on 11 March, 2020 [2].

Highly pathogenic human corona viruses infections suppress type I interferon (IFN) production and signaling, the key component of host antiviral defense in the early phase of viral replication, thus exacerbating disease progression. In line with SARS and MERS, SARS-CoV-2 infection in severe cases involves the host response as an important contributor to the disease process and tissue damage, mainly due to dysregulated and excessive innate immune responses [3]. The primary immune response leads to viral clearance in most cases.

In a subgroup of patients, the secondary immune response may be exaggerated, leading to inflammatory-induced lung injury and complications including pneumonitis, acute respiratory distress syndrome, respiratory failure, shock, organ failure, and potentially death [4]. This exaggerated response is considered a "cytokine storm", so diagnostic suspicion is generally made on clinical signs and symptoms (fever, fatigue, dry cough, anorexia, dyspnea, rhinorrhea, and anosmia) and confirmed by polymerase chain reaction tests on nasopharyngeal and oropharyngeal swabs or sputum [5].

There is no available evidence that supports discontinuation of biologic treatment of psoriasis for most patients simply because of the risk of infection [6]. According to the results of randomized clinical trials of biological agents in psoriasis, the rates of nasopharyngitis and upper respiratory tract infections are similar to placebo.

Vitamin D has an anti-inflammatory effect, and stimulates innate immunity against infectious agents. It inhibits the production of pro-inflammatory cytokines and downregulate NF$\mathrm{KB}$. Therefore, vitamin $\mathrm{D}$ deserves consideration in the treatment of COVID-19 [7].
Some authors have proposed a classification of immunomodulators and immunosuppressants according to "likely risk", suggesting continuation of TNF $\alpha$ inhibitors and antill biologics ("likely moderate risk") in the presence of mild viral symptoms. Other authors recommend a limitation or avoidance of cyclosporine, methotrexate, and TNF $\alpha$ inhibitors for dermatologic patients in areas with high infection rates and stopping all immunosuppressive and biological therapy when exposure to confirmed COVID-19 cases occurs. Finally, some authors propose that the use of biologic therapies that modulate T helper (Th)-1 response, such as TNF $\alpha$ inhibitors, abatacept and ustekinumab, might specifically require more stringent precautions [8].

Therefore, at the current time, the following guidance may be given to patients with psoriasis:

- All patients should be reminded to practice good infection prevention measures such as frequent hand washing, social distancing, and the use of telehealth resources when available.

- There is no evidence to recommend prophylactically stopping or postponing biologic therapy in all patients with psoriasis; however, patients should have individualized discussions with their medical providers taking into account the following factors:

- -COVID-19 risk factors such as older age, cardiovascular disease, hypertension, lung disease, diabetes, or cancer

- Severity of underlying psoriasis or psoriatic arthritis

*Corresponding author: Ahmed M. Abbas, Department of Obstetrics \& Gynecology, Faculty of Medicine, Assiut University; Covid-19 Research of Assiut University Association (CORAUNA) group, Egypt

Accepted: November 10, 2020

Published online: November 12, 2020

Citation: Abbas AM, Zaki ZY (2020) Biologic Therapy for Psoriasis in the Era of COVID-19 Pandemic: To Stop or to Continue?. Dermatol Arch 4(1):93-94

Copyright: (c) 2020 Abbas AM, et al. This is an open-access article distributed under the terms of the Creative Commons Attribution License, which permits unrestricted use, distribution, and reproduction in any medium, provided the original author and source are credited. 
- Concomitant immunosuppressive medications or conditions

- Risk of exposure to COVID-19 based on occupation or living situation

- If a reduction in immunosuppressive treatment is desired, options include: Temporary discontinuation of the biologic, reduction in biologic dose frequency, Transition to an alternative biologic, reduction or discontinuation of concomitant immunosuppressants (e.g., methotrexate), Increase in use of topical agents, home phototherapy, or other non-immunosuppressive medications

- Patients who test positive for COVID-19 infection should be advised to hold their biologic dose until their infection clears. This requires resolution of fever without the use of fever-reducing medications, improvement in respiratory symptoms (e.g., cough, shortness of breath), and two negative COVID-19 test performed $24 \mathrm{~h}$ apart. However, if COVID-19 retesting is not available, then a conservative approach would be to avoid restarting biologic therapy until 30 days after resolution of fever and respiratory symptoms.

- The risks and benefits of initiating biologic therapy should be considered on an individual patient basis.

\section{Acknowledgement}

None.

\section{Statement of Ethics}

The letter does not need formal ethical approval.

\section{Disclosure Statement}

The authors state that there are no conflicts of interest.

\section{Funding Sources}

None.

\section{Author Contributions}

Both authors contribute equally in the design, writing and revision of the article.

\section{References}

1. Park SE (2020) Epidemiology, virology, and clinical features of severe acute respiratory syndrome-coronavirus-2 (SARS-CoV-2; Coronavirus Disease-19). CEP 63: 119-124.

2. (2020) Coronavirus disease (COVID-19) pandemic. World Health Organization.

3. Prompetchara E, Ketloy C, Palaga T (2020) Immune responses in COVID-19 and potential vaccines: Lessons learned from SARS and MERS epidemic. Asian Pac J Allergy Immunol 38: 1-9.

4. Gee K, Guzzo C, Mat C, et al. (2009) The IL-12 family of cytokines in infection, inflammation and autoimmune disorders. Inflammation \& Allergy-Drug Targets 8: 40-52.

5. Huang C, Wang Y, Li X, et al. (2020) Clinical features of patients infected with 2019 novel coronavirus in Wuhan, China. The Lancet 395: 497-506.

6. Bashyam AM, Feldman SR (2020) Should patients stop their biologic treatment during the COVID-19 pandemic. J Dermatolog Treat 19: 1-2.

7. Slominski XA, Slominski RM, Goepfert PA, et al. (2020) COVID-19 cytokine storms perhaps better stopped by the CYP11A1 Vitamin D pathway-Aug 11, 2020. Exp Dermatol.

8. Sriwijitalai W, Wiwanitkit $\mathrm{V}$ (2020) Biological treatment during COVID-19 outbreak. J Dermatolog Treat 28: 1-2.

DOI: $10.36959 / 661 / 310$

Copyright: (C) 2020 Abbas AM. This is an open-access article distributed under the terms of the Creative Commons Attribution License, which permits unrestricted use, distribution, and reproduction in any medium, provided the original author and source are credited. 